\title{
The German Standard and Short Authentic and Hubristic Pride Scales
}

\section{Psychometric Properties, Validity Testing, Self-Other Agreement, and Linguistic Correlates}

\author{
Robert Körner@ and Astrid Schütz@ \\ Department of Psychology, University of Bamberg, Germany
}

\begin{abstract}
The authentic and hubristic pride (A\&HP) model is the domineering paradigm in pride research. Authentic pride (AP) comprises feelings of accomplishment and self-worth, whereas hubristic pride (HP) includes conceit and arrogance. We provide a German version of the A\&HP scale (Tracy \& Robins, 2007), the GAHPS. We found a good fit for a two-factor solution. Internal consistencies were high. Nomological validity was supported for personality, self-esteem, and narcissism (Study 1, $N=569$ ), status (Study 2, $N=565$ ), and other emotions (Study 3 , $N=204)$. In Study $4(N=184)$, AP and HP had different associations with prosocial and antisocial behavior. We found high self-other agreement (109 dyads) for AP but not for HP. Further, people used different words to describe AP and HP when they described themselves and peers, thus suggesting that the two forms are associated with different linguistic styles. Finally, using an Ant Colony Optimization algorithm, we derived a short form for the scale. Researchers are advised to choose the standard or short scale, depending on the research purpose. This research broadens the validity testing of the A\&HP model and, for the first time, provides linguistic correlates of the two forms of pride.
\end{abstract}

Keywords: authentic pride, hubristic pride, self-conscious emotion, LIWC, status
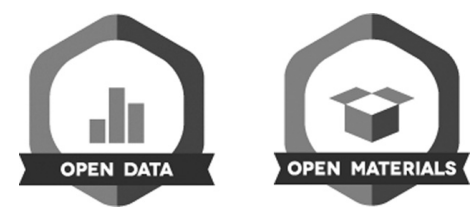

Pride is a self-conscious emotion that serves social functions. Self-conscious emotions require self-evaluative processes and a unique sense of self. They help people attain social goals and regulate group living (Tracy \& Robins, 2004). Yet, pride is considered selfish by some, whereas others think it is an appropriate emotion after accomplishments.

The authentic and hubristic pride (A\&HP) model captures this dual nature of pride (Tracy \& Robins, 2007): Authentic pride (AP) is conceptualized as prosocial and achievement-oriented, hubristic pride (HP) as self-aggrandizing - and the latter is described with terms such as conceit or arrogance. The A\&HP model is increasingly used by social and personality psychologists and anthropologists to understand adaptive and maladaptive aspects of pride. Its relevance for organizational and business contexts has also been demonstrated (e.g., McFerran et al., 2014;
Schaumberg \& Tracy, 2020). For example, AP is positively related to advice-giving and generosity, and HP relates to prejudice and anger. Both forms are associated with leadership emergence, but they follow different routes (dominance vs. prestige; Cheng et al., 2010; Schaumberg \& Tracy, 2020). Moreover, AP is associated with healthy relationship functioning and mental health (e.g., perceived social support, low attachment avoidance, and anxiety), and HP is linked to antisocial behaviors, trait anxiety, low authenticity, and dysfunctional interpersonal attitudes and behaviors (Carver et al., 2010; Tracy et al., 2009).

Since 2007, researchers have used the 14-item A\&HP scale, cited more than 900 times (June 2021; Tracy \& Robins, 2007). Despite the broad use of the A\&HP scale in several languages (e.g., Chinese: Liu et al., 2016; German: Sullivan \& Dumont, 2014; Polish: Rogoza et al., 2018), only English-language scale scores have been validated. We aimed to provide evidence for the validity of scores derived from the German-language standard version (14 items) and developed a short version (six items) - the GAHPS and GAHPS-S, respectively. The availability of a psychometrically sound instrument in German will allow 
for increased confidence in research findings and crosscultural research.

We conducted an in-depth test of the psychometric properties. Regarding validity, we aimed to replicate associations with constructs that are related to pride in the past (e.g., personality or narcissism; see Tracy \& Robins, 2007) but also to provide correlations with variables that have not yet been related to pride (e.g., socioeconomic status [SES], greed, optimism) to expand the explanatory power of the A\&HP model. Furthermore, we examined correlations between self-reported pride and constructs measured with objective methods (behavior in prosocial scenarios, implicit measurement of affect, SES). Additionally, to contribute to the literature on interpersonal perception of emotions, we aimed to evaluate self-other agreement (SOA) coefficients in well-acquainted dyads. Further, participants were asked to briefly explain the reasons for their assessment of self-rated (and peer-rated) pride. The latter was done to understand whether the two forms of pride are associated with distinct linguistic markers. We used a linguistic analysis program to provide what we believe is the first evidence for linguistic correlates of self-and observer-perceived A\&HP.

\section{Overview of Studies}

We conducted four studies. In Studies 1 and 2, we tested the psychometric properties of the GAHPS. These studies had large sample sizes to allow for confirmatory factor analysis (CFA). Additionally, we tested for measurement invariance across gender. Regarding nomological validity, we examined correlations with personality, self-esteem, narcissism (Study 1), status (Study 2), other emotions (Study 3), and prosocial and antisocial behavior (Study 4). Moreover, in Study 3, we examined the temporal stability of the GAHPS. Study 4 provides self-other agreement (SOA) coefficients and examined linguistic correlates of the two forms of pride. Finally, we present a short form of the GAHPS.

\section{Study 1 - Pride and Personality}

In Study 1, we tested the psychometric properties and nomological validity of the GAHPS scores. We expected a good fit for a two-factor solution. In line with past research (Tracy \& Robins, 2007), we expected positive associations between AP and all Big Five traits except neuroticism. Neuroticism was hypothesized to correlate negatively with AP. HP was expected to correlate negatively with conscientiousness and agreeableness. As AP is understood as the affective core of genuine self-esteem and HP as the affective core of grandiose narcissism (Tracy et al., 2009), we tested these associations. Moreover, in distinguishing dimensions of narcissism (Back et al., 2013), we assumed that admiration would be positively correlated with both forms of pride but that rivalry would be negatively associated with AP and positively associated with HP (Rogoza et al., 2018).

\section{Method}

\section{Participants and Procedure}

We used data from a research project on power (Körner et al., 2021; Study 1). The authors had assessed A\&HP and various psychological constructs of which we considered personality, self-esteem, and narcissism relevant for our research purposes. All analyses, findings, and conclusions that we present are novel.

Participants were recruited at a distance-learning university (University of Hagen). This approach ensured a heterogeneous sample regarding age and professional background. Participants lived all over Germany. Data prepa-ration is described (Körner et al., 2021). Overall, 569 participants (80\% women, $19 \%$ men; $M_{\text {age }}=32.12$, $S D_{\text {age }}=10.16$, Range: $\left.18-75\right)$ completed the pride measure .

\section{Instruments}

We used the German-language A\&HP items by Sullivan and Dumont (2014) and compared them with results of our own translation/back-translation procedure (in line with the Guidelines for Translating and Adapting Tests by the International Test Commission, 2017) with a bilingual native English speaker. As there were only minor discrepancies, we decided to keep Sullivan and Dumont's item wordings. Table 1 presents the items and response format. Table 2 contains Cronbach's $\alpha$ coefficients for all scales. Detailed scale descriptions are available at https://osf.io/eh7r4/.

The Big Five were assessed with the NEO-FFI-30 (Körner et al., 2008), self-esteem with the Rosenberg SelfEsteem Scale (Von Collani \& Herzberg, 2003), and grandiose narcissism with the Narcissistic Personality Inventory (Schütz et al., 2004). Further, we used the Narcissistic Admiration and Rivalry Questionnaire (Back et al., 2013).

\section{Data Analysis Strategy}

First, we examined item statistics, the fit of a two-factor model, and internal consistencies using Cronbach's $\alpha$ and McDonald's $\omega$. Model fit was assessed with a CFA containing correlated latent variables. WLSMV estimation was used as it is the preferred method for ordinal data and is somewhat superior to ML estimation with respect to factor loadings and standard errors (Beauducel \& Herzberg, 2006). Residuals of the indicator variables were uncorrelated. 
Table 1. Item statistics, corrected item-total correlations $\left(r_{i t}\right)$, and loadings of the GAHPS items

\begin{tabular}{|c|c|c|c|c|c|c|c|c|c|}
\hline & \multirow[b]{2}{*}{ Item } & \multicolumn{4}{|c|}{ Study 1} & \multicolumn{4}{|c|}{ Study 2} \\
\hline & & M & $S D$ & $r_{\text {it }}$ & Loading & M & $S D$ & $r_{\text {it }}$ & Loading \\
\hline $1-A P$ & Ich habe das Gefühl, dass ich etwas geschafft habe. [accomplished] & 3.40 & 0.94 & .70 & .87 & 3.38 & 1.00 & .77 & .89 \\
\hline 2-HP & Ich bin arrogant. ${ }^{S}$ [arrogant] & 1.75 & 0.89 & .66 & .86 & 1.61 & 0.78 & .69 & .89 \\
\hline $3-\mathrm{HP}$ & Ich bin eingebildet. ${ }^{S}$ [conceited] & 1.72 & 0.90 & .68 & .88 & 1.58 & 0.81 & .65 & .87 \\
\hline 4-AP & Ich bin zuversichtlich. [confident] & 3.63 & 0.93 & .60 & .68 & 3.66 & 0.97 & .66 & .70 \\
\hline $5-\mathrm{HP}$ & Ich bin geltungsbedürftig. [egoistical] & 2.57 & 1.08 & .47 & .58 & 2.48 & 1.04 & .40 & .50 \\
\hline $6-A P$ & Ich habe ein erfülltes Leben. ${ }^{S}$ [fulfilled] & 3.62 & 0.98 & .68 & .76 & 3.62 & 1.00 & .71 & .77 \\
\hline 7-AP & Ich verfüge über Selbstwertgefühl. [like I have self-worth] & 3.48 & 1.00 & .64 & .74 & 3.50 & 1.05 & .68 & .73 \\
\hline $8-A P$ & Ich habe das Gefühl, etwas erreicht zu haben. ${ }^{S}$ [like I am achieving] & 3.44 & 1.07 & .82 & .96 & 3.39 & 1.03 & .80 & .94 \\
\hline 9-HP & Ich bin wichtigtuerisch. [pompous] & 1.79 & 0.93 & .66 & .78 & 1.68 & 0.86 & .64 & .75 \\
\hline 10-AP & Ich bin produktiv. ${ }^{\mathrm{S}}$ [productive] & 3.66 & 0.89 & .56 & .65 & 3.77 & 0.89 & .48 & .52 \\
\hline 11-HP & Ich bin selbstgefällig. [smug] & 1.95 & 0.97 & .63 & .76 & 1.85 & 0.96 & .62 & .73 \\
\hline 12-HP & Ich bin hochnäsig. ${ }^{\mathrm{S}}$ [stuck-up] & 1.49 & 0.79 & .66 & .83 & 1.35 & 0.69 & .64 & .83 \\
\hline $13-A P$ & Ich habe das Gefühl, erfolgreich zu sein. [successful] & 3.03 & 1.02 & .73 & .83 & 3.00 & 1.07 & .76 & .87 \\
\hline $14-\mathrm{HP}$ & Ich bin protzig. [snobbish] & 1.40 & 0.73 & .58 & .78 & 1.32 & 0.62 & .55 & .72 \\
\hline
\end{tabular}

Note. $\mathrm{AP}=$ authentic pride; $\mathrm{HP}=$ hubristic pride. Responses were given on the following scale: $1=$ überhaupt nicht, $2=$ ein bisschen, $3=$ mittelmäßig, $4=$ eher stark, 5 = extrem stark. ${ }^{S}$ GAHPS-S items. The original English items are presented in brackets below each German item and are reprinted here from Tracy and Robins (2007) with the permission of the authors.

Table 2. Nomological validity of the GAHPS

\begin{tabular}{|c|c|c|c|c|c|}
\hline & \multirow[b]{2}{*}{ Cronbach's $\alpha$} & \multicolumn{2}{|c|}{ Zero-order correlations } & \multicolumn{2}{|c|}{ Partial correlations } \\
\hline & & AP & $\mathrm{HP}$ & AP & $\mathrm{HP}$ \\
\hline Openness & .78 & $.09 *$ & -.03 & $.09 *$ & -.03 \\
\hline Conscientiousness & .75 & $.40 * \star \star$ & $-.19 * \star \star$ & $.42 * \star \star$ & $-.23 * * *$ \\
\hline Extraversion & .76 & $.55^{\star \star \star}$ & $.18^{\star \star \star}$ & $.53 * \star \star$ & $.12 \star \star$ \\
\hline Agreeableness & .73 & $.14^{\star \star}$ & $-.51 \star \star \star$ & $.20 * \star \star$ & $-.53^{\star * \star}$ \\
\hline Neuroticism & .84 & $-.66^{\star \star \star}$ & .06 & $-.67 \star \star \star$ & $.13^{\star \star}$ \\
\hline Self-esteem & .90 & $.76 * \star \star$ & -.03 & $.71 * \star \star$ & $-.23 * \star \star$ \\
\hline Grandiose narcissism & $.78^{\mathrm{a}}$ & $.33 * \star \star$ & $.43 * \star \star$ & .07 & $.45^{\star \star \star}$ \\
\hline Admiration & .80 & $.24^{\star \star \star}$ & $.50 * \star \star$ & $.31 * \star \star$ & $.25^{\star \star *}$ \\
\hline Rivalry & .66 & $-.09 *$ & 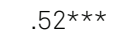 & $-.28 * \star \star$ & $.33 * * *$ \\
\hline Dominance & .80 & .02 & $.44^{\star \star \star}$ & $-.12^{\star \star}$ & $.44 * \star \star$ \\
\hline Prestige & .90 & $.65^{\star \star \star}$ & .08 & $.65^{\star \star \star}$ & -.04 \\
\hline SES & .65 & $.20 * \star \star$ & .01 & $.19 * \star \star$ & -.01 \\
\hline Aggression & .91 & 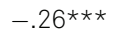 & $.43^{\star \star \star}$ & $-.24 \star \star$ & $.42^{\star \star \star}$ \\
\hline Physical aggression & .76 & -.12 & $.26 * \star \star$ & -.10 & $.25^{\star \star}$ \\
\hline Verbal aggression & .71 & -.03 & $.40 * \star \star$ & .00 & $.40 * \star \star$ \\
\hline Anger & .84 & $-.25^{\star \star}$ & $.41 * \star \star$ & $-.23^{* *}$ & $.40 * \star \star$ \\
\hline Mistrust & .80 & $-.36 * \star \star$ & $.33 * \star \star$ & $-.34^{\star \star \star}$ & $.31 * \star \star$ \\
\hline Machiavellianism & .81 & $-.19 *$ & 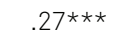 & $-.15^{\star}$ & .11 \\
\hline Psychopathy & .71 & -.11 & $.37 * \star \star$ & -.01 & $.28 * \star *$ \\
\hline Prosocial behavior friend & - & .00 & -.09 & -.01 & -.09 \\
\hline Prosocial behavior stranger & - & $.16^{\star}$ & -.11 & $.15^{\star}$ & -.10 \\
\hline
\end{tabular}

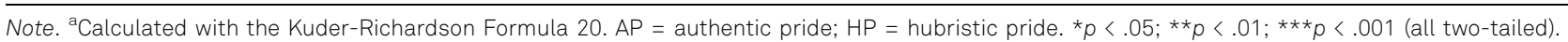

Item-factor assignments were adopted from Tracy and Robins (2007). We chose the following cut-offs as markers of adequate model fit: RMSEA $\leq .08$ (Browne \& Cudeck, 1993); CFI and TLI $\geq .90$ (Marsh et al., 2004). Further, we expected fit indices comparable to Tracy and Robins
(2007), who reported the following for the English A\&HP scale: $\chi^{2}(75)=267.24$, RMSEA $=.084, p<.001 ; \chi^{2}(75)=$ 239.11, RMSEA $=.079, p<.001$.

We then computed zero-order and partial correlation coefficients for validity testing. Regarding partial correlations, 
we computed new variables to account for shared variance. We regressed authentic on hubristic pride, and vice versa, self-esteem on grandiose narcissism, and vice versa, and admiration on rivalry, and vice versa, and we saved the standardized residuals. The resulting residualized variables were correlated with each other. In the following, we report partial correlations unless otherwise stated. ${ }^{1}$ We interpreted correlations of $.10-.30$ as small, .30 to .50 as a medium, and $>.50$ as large (Cohen, 1988). Item and correlational analyses were done with SPSS 25 . The CFA was computed with Mplus 7. RStudio 1.2.5019 was used for McDonald's $\omega$ with a robust maximum-likelihood estimator (MBESS package; Kelley, 2018). Data, syntaxes, and materials (for all studies) are available at https://osf.io/eh7r4/.

\section{Results}

\section{Psychometric Properties}

Table 1 presents the item characteristics of the GAHPS items. Corrected item-total correlations were good for AP $\left(.56 \leq r_{\text {it }} \leq .82\right)$ and HP $\left(.47 \leq r_{\text {it }} \leq .68\right)$. Model fit was satisfactory, $\chi^{2}(76)=417.281, p<.001$; RMSEA $=.089,90 \%$ CI $[.081, .097], p<.001 ;$ CFI $=.969$; TLI $=.962$. All loadings (see Table 1 ) were significant $(p s<.001)$. The factor intercorrelation was $r=.18$. Internal consistency was high for AP and HP $(\alpha=.89 / .85, \omega=.89 / .85)$.

\section{Nomological Validity}

AP was positively associated with age $(r(563)=.18, p<$ .001), whereas HP was negatively correlated with age $(r(563)=-.13, p=.001)$. Gender (male/female) was not found to have strong associations with $\mathrm{AP}(r(559)=-.04$, $p=.408)$ or $\mathrm{HP}(r(559)=-.12, p=.007)$. Mean differences between men and women were negligible for AP (Hedges's $g=-0.09)$ but stronger for HP $(g=-0.29)$.

AP was positively associated with conscientiousness $(r(563)=.42, p<.001)$, extraversion $(r(563)=.53, p<$ $.001)$, and agreeableness $(r(563)=.20, p<.001)$ and negatively associated with neuroticism $(r(563)=-.67, p<$ .001). Both AP and HP showed no strong correlations with openness $(r(563)=.09, p=.037 ; r(563)=-.03, p=.420)$. Like AP, HP was positively correlated with extraversion $(r(563)=.12, p=.003)$, but the relation was significantly smaller $(Z=11.83, p<.001)$. Contrary to AP, HP was negatively associated with conscientiousness $(r(563)=-.23, p<$ $.001)$ and agreeableness $(r(563)=-.53, p<.001)$, and there was only a minor positive association with neuroticism $(r(563)=.13, p=.002)$.
Genuine self-esteem (i.e., when the variance shared between narcissism and self-esteem was partialled out) was positively associated with AP $(r(563)=.71, p<.001)$. Unadjusted self-esteem (not controlling for narcissism) was not associated with HP $(r(563)=-.03, p=.553)$, but when the variance shared between AP and HP was partialled out, genuine self-esteem was negatively associated with HP $(r(563)=-.23, p<.001)$. Thus, the variance shared between narcissism and self-esteem and between AP and HP obfuscated the negative link between HP and genuine self-esteem. This finding dovetails with the correlational pattern for narcissism: Hubristic pride was positively associated with grandiose narcissism (i.e., self-esteem was partialled out; $r(563)=.45, p<.001)$. The zero-ordercorrelation between AP and narcissism was significantly positive $(r(563)=.33, p<.001)$, but it became nonsignificant when HP and self-esteem were partialled out $(r(563)=.07, p=.118)$. Admiration (controlled for rivalry) was positively associated with AP $(r(563)=.31, p<.001)$ and HP $(r(563)=.25, p<.001)$. Yet, rivalry was negatively associated with AP $(r(563)=-.28, p<.001)$ and positively associated with HP $(r(563)=.33, p<.001)$.

\section{Discussion}

The results supported a good model fit for the two pride facets. Only the RMSEA was slightly above the cut-off probably because the data were not normally distributed. Internal consistencies were high. Nomological validity was supported. Interestingly, AP showed the strongest associations with extraversion and emotional stability, but agreeableness was not as strongly associated with AP as the aforementioned traits were. HP correlated highest with disagreeableness, which is in line with previous research (Tracy \& Robins, 2007). The pattern of correlations with self-esteem and all narcissism scales is in line with past studies (Rogoza et al., 2018; Tracy et al., 2009) and provides evidence for the antisocial and self-aggrandizing nature of HP and the relevance of genuine self-worth and admiration for AP.

\section{Study 2 - Pride and Status}

In Study 2, we checked the psychometric properties of the GAHPS in a second independent sample. Further, we tested for measurement invariance across gender and studied

\footnotetext{
${ }^{1}$ It might be argued that other variables should also be partially out to have, for example, genuine self-esteem. However, accounting for the variance shared with many other variables may artificially decrease associations between two variables. Thus, we followed Tracy and Robins' (2007; see also Cheng et al., 2010; Tangney et al., 2000) approach by only removing the variance shared with one variable and simultaneously providing zero-order correlations to include information about the changes in the magnitudes of correlations.
} 
associations of the pride dimensions with objective SES, and two pathways followed to obtain social rank (i.e., dominance and prestige).

Pride is the emotion most closely tied to social status. Status can be attained via two pathways: Dominance describes the use of force and coercion to achieve rank, whereas prestige describes status ascribed to people because of their skills and expertise (Cheng et al., 2010). Specifically, while research suggests that AP motivates behaviors geared toward attaining prestige-based status, HP motivates behaviors that are beneficial for attaining dominance-based status (Cheng et al., 2010). In line with these findings, we expected positive associations between AP and prestige and HP and dominance. Furthermore, we assumed a positive association between AP and SES because factors constituting SES (e.g., education and professional achievements) should be more strongly related to prestige and AP, both of which are based on accomplishments and competencies.

\section{Method}

We recruited students attending a distance-learning university. They lived all over Germany. Participants who had implausibly fast responses ( $<2 \mathrm{~s}$ per item; 21 people) and who almost always ticked the same answer (e.g., always ticking "not at all," seven people) were excluded. The final sample comprised 565 participants $(81.3 \%$ women, $18.4 \%$ men; $M_{\text {age }}=30.32, S D_{\text {age }}=9.00$, Range: $\left.18-61\right)$. The questionnaire began with sociodemographic questions, followed by the pride items, then the Dominance-Prestige Scales (Cheng et al., 2010). Participants were offered course credit for completing the questionnaire. SES was based on profession, net income, and educational/vocational qualifications (see Lampert et al., 2013).

\section{Results}

\section{Psychometric Properties}

Table 1 presents the item characteristics. Corrected itemtotal correlations were satisfactory for AP $\left(.48 \leq r_{\text {it }} \leq .80\right)$ and HP (.40 $\left.\leq r_{\text {it }} \leq .69\right)$. Good model fit was supported in this second sample, $\chi^{2}(76)=305.558, p<.001$; RMSEA $=$ $.073,90 \%$ CI $[.065, .082], p<.001$; CFI $=.981$; TLI $=$ .977 . All loadings (see Table 1 ) were significant ( $p s<.001)$. The factor intercorrelation was $r=.08$. Internal consistency was high for AP and HP $(\alpha=.89 / .83, \omega=.90 / .83)$.

Using multigroup CFA (WLSMV estimator), we examined measurement invariance across gender (male/female; see the Online Supplement for the analysis strategy; Körner \& Schütz, 2021). We merged the data from Studies 1 and 2 to have a sample size $>200$ for men. With respect to the invari- ance criterion by Cheung and Rensvold $(2002 ; \Delta C F I \leq .01)$, we found strict measurement invariance (see Table 3 ).

\section{Nomological Validity}

For validity testing, we controlled for the variance shared between AP and HP. We also partialled out the variance shared between dominance and prestige. AP was weakly negatively related to dominance $(r(563)=-.12, p=.006)$ and strongly positively related to prestige $(r(563)=.65$, $p<.001)$. By contrast, HP was unrelated to prestige $(r(563)=-.04, p=.308)$ and positively related to dominance $(r(563)=.44, p<.001)$. SES was positively correlated with $\mathrm{AP}(r(384)=.19, p<.001)$ but unrelated to $\mathrm{HP}(r(384)=$ $-.01, p=.889)$.

\section{Discussion}

To sum up, the GAHPS showed good model fit and invariance across gender (i.e., equal dimensionality, loadings, intercepts, and residual variances). As expected and in line with past research (Cheng et al., 2010), we found strong links between AP and prestige and HP and dominance. This adds to the accumulating findings that demonstrate the relevance of different forms of pride for different status strategies. Further, SES as an objective measure of status was related only to AP. Either the experience of high AP helps people strive for and gain a highly respected job, high income, and high education, or the attainment of the aforementioned factors may aid the development of AP. Both avenues are likely relevant (see also Weidman et al., 2016).

\section{Study 3 - Pride and Other Emotions}

In Study 3, we tested associations between A\&HP and other self-conscious emotions and related constructs. Shame has been reported to be negatively associated with AP but positively associated with HP. On the other hand, guilt should be positively related to AP and negatively related to HP (Tracy \& Robins, 2007). We aimed to replicate these effects. Moreover, AP (HP) was expected to be positively correlated with benign (malicious) envy (Lange \& Crusius, 2015a).

Past research has demonstrated that both forms of pride cannot simply be explained by valence-based differences, which means that AP is not solely a positive component of pride and HP is not a negative one (Tracy \& Robins, 2007). Thus, we did not expect reverse correlational patterns of the GAHPS with affect. Instead, we hypothesized only weak associations of both forms of pride with positive 
Table 3. Tests of measurement invariance for gender (male/female)

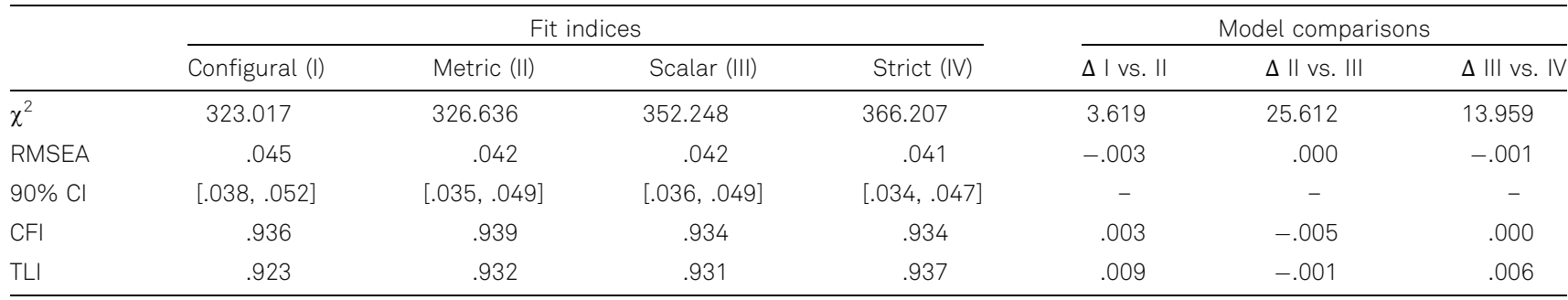

Note. RMSEA = Root Mean Square Error of Approximation; CFI = Comparative Fit Index; TLI = Tucker-Lewis Index.

(PA) and negative affect (NA). Additionally, we expected both forms of pride to be positively correlated with greed because AP is linked to the consumption of luxury goods (McFerran et al., 2014), and there is correlational evidence that luxury consumption is linked to greed (Guido et al., 2020; Liu et al., 2019). Further, the personality pattern of HP is typical of greed (Seuntjens et al., 2015). We also expected optimism to be positively correlated with AP because confidence and accomplishments are central to AP (Tracy \& Robins, 2007). Moreover, we tested for the temporal stability of the scale over one month.

\section{Method}

\section{Participants and Procedure}

Participants were mostly undergraduates at a German university who were recruited via email lists and social media. They completed an online survey. Two participants with suspiciously fast responses (Leiner, 2019) were excluded. The final sample comprised 204 participants (78.9\% women, $20.6 \%$ men; $M_{\text {age }}=25.28, S D_{\text {age }}=10.65$, Range: 16-74). We retested them four weeks later. In total, data from 60 participants could be matched (78.3\% women, $21.7 \%$ men; $M_{\text {age }}=22.95, S D_{\text {age }}=7.67$, Range: 18-67). Participants were offered course credit for completing the questionnaires.

\section{Instruments}

Shame and guilt were assessed with the Test of SelfConscious Affect (TOSCA-3; Tangney et al., 2000), envy with the Benign and Malicious Envy Scale (Lange \& Crusius, 2015b), greed with the Dispositional Greed Scale (Seuntjens et al., 2015), and optimism with the LifeOrientation-Test (Glaesmer et al., 2008). Affect was assessed with the Implicit Positive and Negative Affect Test (Quirin et al., 2009). This is an objective personality test: Participants rate the extent $(1=$ does not fit at all to $4=$ fits very well) to which six artificial words (e.g., "TALEP") express certain emotions using six adjectives (three positive, three negative) for each artificial word. Positive (negative) affect is the average agreement with the three positive (negative) emotion words across all six artificial words.

\section{Results}

Internal consistency was high for AP and HP $(\alpha=.85 / .85$, $\omega=.85 / .85)$. The 4 -week stability was high for AP and $\mathrm{HP}, r_{\mathrm{tts}}(58)=.84 / .81, p \mathrm{~s}<.001$. We controlled for variance shared between AP and HP, between shame and guilt, and between benign envy and malignant envy. As expected, AP was positively correlated with shame-free guilt $(r(202)=$ $.23, p=.001)$ and benign envy $(r(202)=.24, p=.001)$ and negatively correlated with guilt-free shame $(r(202)=$ $-.42, p<.001)$. HP was negatively related to shame-free guilt $(r(202)=-.33, p<.001)$ and positively related to guilt-free shame $(r(202)=.16, p=.023)$ and malicious envy $(r(202)=.38, p<.001$; see Table 4$)$.

AP showed no strong relations with PA or NA, but HP was somewhat positively related to PA $(r(198)=.16, p=$ .022). As expected, greed was positively related to HP $(r(202)=.38, p<.001)$, but contrary to our hypothesis, AP was not significantly correlated with greed $(r(202)=$ $-.13, p=.069)$. Optimism was strongly positively associated with $\mathrm{AP}(r(201)=.58, p<.001)$.

\section{Discussion}

The A\&HP scale scores showed high temporal stability over one month. They were distinct from, but as expected, somewhat related to other self-conscious emotions (shame, guilt, envy). AP was largely unrelated to PA/NA, but HP showed a small positive association with PA. It is possible that HP, as assessed with the GAHPS, has a somewhat larger implicit affective component than AP. However, future research should test whether A\&HP show the same associations with implicit affect as with explicit affect. Furthermore, only HP was positively associated with greed. This finding underscores the relevance of distinguishing between the two forms of pride and provides evidence for the maladaptive core of HP. Optimism was very closely 
Table 4. Nomological validity of the GAHPS regarding emotions (Study 3)

\begin{tabular}{|c|c|c|c|c|c|}
\hline & \multirow[b]{2}{*}{ Cronbach's $\alpha$} & \multicolumn{2}{|c|}{ Zero-order correlations } & \multicolumn{2}{|c|}{ Partial correlations } \\
\hline & & AP & $H P$ & $\mathrm{AP}$ & $H P$ \\
\hline Shame & .82 & $-.35 * \star \star$ & -.06 & $-.42^{\star \star \star}$ & $.16^{\star}$ \\
\hline Guilt & .69 & -.02 & $-.29 * \star \star$ & $.23 * \star \star$ & $-.33 * \star \star$ \\
\hline Benign envy & .82 & $.22 \star \star$ & 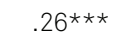 & $.24 \star \star \star$ & .13 \\
\hline Malicious envy & .83 & $-.15^{\star}$ & $.40 * \star \star$ & $-.26 * \star \star$ & $.38 * * *$ \\
\hline Positive affect & .83 & .10 & $.18^{*}$ & .08 & $.16^{*}$ \\
\hline Negative affect & .78 & -.02 & .04 & -.02 & .05 \\
\hline Greed & .80 & -.07 & 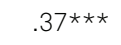 & -.13 & $.38 * * *$ \\
\hline Optimism & .77 & $.59 * \star \star$ & .12 & $.58 * \star \star$ & .03 \\
\hline
\end{tabular}

Note. $\mathrm{AP}=$ authentic pride; HP $=$ hubristic pride. ${ }^{\star} p<.05 ;{ }^{* \star} p<.01 ;{ }^{* \star}{ }^{\star} p<.001$ (two-tailed).

related to AP. Apparently, the AP items tap into optimistic attitudes, and successful people who experience AP may also be more optimistic.

\section{Study 4 - Pride and Prosocial/ Antisocial Attitudes, SOA, and Language Usage}

In Study 4, we aimed to broaden the validity testing of the GAHPS by using several different data sources (self-reports, peer ratings, and verbal descriptions). Relying on different assessment methods has the advantages of reducing method bias and producing more valid results through triangulation (e.g., Campbell \& Fiske, 1959). We expected negative associations for AP and positive associations for HP with self-reported antisocial behavior: aggression, Machiavellianism, and psychopathy (Carver et al., 2010; Costello et al., 2018; Tracy et al., 2009). AP was also expected to be positively correlated and HP negatively correlated with prosocial behavior in scenarios (Wubben et al., 2012). Additionally, we examined SOA coefficients in well-acquainted dyads, and in an exploratory fashion, we analyzed linguistic correlates (i.e., emotion, status, and drive-related words) of both forms of pride.

\section{Method}

\section{Participants and Procedure}

Participants were recruited via social media and word-ofmouth propaganda. One hundred eighty-seven individuals took part (the majority were employees). Participants with unrealistically fast responses (two people; Leiner, 2019) and those who almost always (>90\% of the items) ticked the same answer ( 1 person) were excluded. The final sample comprised 184 participants $\left(78.8 \%\right.$ women; $M_{\text {age }}=33.87$,
$S D_{\text {age }}=12.63$, Range: $\left.19-75\right)$. Participants were instructed to forward a link to a peer-rating questionnaire to a close acquaintance. One hundred nine dyads could be matched. The peer-rater $\left(78.0 \%\right.$ women; $M_{\text {age }}=32.70, S D_{\text {age }}=$ 12.27, Range: 19-67) completed only the GAHPS and provided a short text.

\section{Instruments}

Participants completed the GAHPS, and after each of the two scales, were asked to justify their ratings in two to five sentences. The use of short texts for linguistic analyses and the computation of correlations between linguistic categories with external variables is common practice in personality research (e.g., Brauer \& Proyer, 2020). The peer-rater also completed the scales (observer form) and were likewise asked to justify their ratings. Further, the peer-rater indicated how long they had known the target (in years, months; "duration"), how often they have contact ( $1=$ a few times per year to $5=$ daily, "frequency"), and how well they know the target $(1=$ very little to $5=$ very good, "closeness").

To assess word usage, we used the Linguistic Inquiry and Word Count software (LIWC; Pennebaker et al., 2015). LIWC consists of: a dictionary with more than 90 grammatical and psychological word categories and a processing algorithm that counts words. LIWC output variables refer to percentages of words related to a certain category (e.g., number of anger-related words) in each text. These percentages were correlated with the pride ratings.

Further, we used the German version of the Buss Perry Aggression Questionnaire (Werner \& von Collani, 2014) consisting of four facets: physical aggression, verbal aggression, anger, and mistrust. The Short Dark Triad (Jones \& Paulhus, 2014), assesses psychopathy and Machiavellianism.

Prosocial behavior was captured with nine scenarios, of which five described a person in need (the other four were filler items; for the exact procedure, see Saroglou et al., 2005, or the OSF). There were two conditions: (a) the 
protagonist in the scenarios was a close friend or family member, and (b) the protagonist was a stranger. Participants noted their reactions in 18 hypothetical situations. Answers were coded by two independent raters: $1=$ not prosocial, 2 = somewhat $/$ conditionally prosocial, $3=$ strongly prosocial . As there was high interrater agreement $\left(\kappa_{\mathrm{w}(\text { friend })}=.89\right.$, $\left.\kappa_{\mathrm{w} \text { (stranger) }}=.96\right)$ for a subset $(20 \%)$ of the relevant scenarios, the remaining scenarios were assessed by one rater.

\section{Results}

\section{Nomological Validity}

Internal consistency was high for AP and HP $(\alpha=.89 / .84$, $\omega=.89 / .84)$. We controlled for the variance shared between AP and HP and between Machiavellianism and psychopathy. AP was somewhat negatively correlated with Machiavellianism $(r(182)=-.15, p=.049)$ and showed no relation to psychopathy $(r(182)=-.01, p=.848)$. HP was not significantly associated with Machiavellianism $(r(182)=.11, p=.149)$ and was positively associated with psychopathy $(r(182)=.28, p<.001)$. Overall aggression was negatively related to AP $(r(182)=-.24, p=.001)$ and positively related to HP $(r(182)=.42, p<.001)$. Physical and verbal aggression were not strongly associated with $\mathrm{AP}$, but anger and mistrust were negatively related to AP (see Table 2). HP was positively related to all aggression subscales.

AP was positively correlated with prosocial behavior toward strangers $(r(180)=.15, p=.041)$ but was unrelated to prosocial behavior toward friends $(r(179)=-.01, p=$ .897). By contrast, HP was slightly negatively related to prosociality toward friends $(r(179)=-.09, p=.221)$ and strangers $(r(180)=-.10, p=.174)$. The correlations did not differ for friends $(Z=0.01, p=.461)$ but did for strangers $(Z=2.40, p=.008)$.

\section{Self-Other Agreement}

Internal consistency of the peer-rating version was good (AP: $\alpha=.86, \omega=.86$; HP: $\alpha=.95, \omega=.96$ ). SOA correlation coefficients were high for AP (.45) but low for HP (.17). Additionally, we carried out multiple linear hierarchical regression models (controlling for duration, frequency (Step 1), and closeness (Step 2), self-rated pride entered in Step 3). We found that SOA remained largely unchanged (AP: $\beta=$ $.45, p<.001$; HP: $\beta=.20, p=.044$; see Tables S1, S2 in the Online Supplement; Körner \& Schütz, 2021). Further, there were no mean differences between self- and peer-ratings for $\mathrm{AP}, t(108)=-1.613, p=.110$, or $\mathrm{HP}, t(108)=$ $-0.999, p=320$.

\section{Linguistic Analyses}

LIWC2015 recognized $85 \%_{\text {AP-self }} / 82 \%_{\text {HP-self }} / 86 \%_{\text {AP-peer }} /$ $84 \%_{\text {HP-peer }}$ of all words. The mean descriptions were
Table 5. Linguistic correlates of the GAHPS

\begin{tabular}{|c|c|c|c|c|}
\hline \multirow[b]{2}{*}{ Word category } & \multicolumn{2}{|c|}{ Self-rating } & \multicolumn{2}{|c|}{ Peer-rating } \\
\hline & AP & $\mathrm{HP}$ & AP & $\mathrm{HP}$ \\
\hline Tone & $.21 * \star$ & -.05 & $.19 * *$ & -.05 \\
\hline Clout & .00 & .02 & $.33 * * *$ & .10 \\
\hline Positive emotion & .08 & -.05 & .10 & .02 \\
\hline Negative emotion & $-.29 * \star \star$ & .04 & $-.32 * \star \star$ & $20^{\star}$ \\
\hline Anxiety & $-.19 * \star$ & -.07 & $-.33^{\star \star *}$ & -.11 \\
\hline Anger & -.01 & .02 & -.02 & .11 \\
\hline Sadness & $-.19 *$ & $.16^{*}$ & -.15 & .12 \\
\hline Affiliation & .01 & .04 & $.20 *$ & -.07 \\
\hline Achievement & -.03 & $.27 * \star \star$ & $.25 * *$ & $.29 * \star$ \\
\hline Power & -.04 & -.07 & -.06 & $.22^{\star}$ \\
\hline Reward & -.11 & .02 & $.36 * \star \star$ & $.47^{\star \star \star}$ \\
\hline Risk & -.01 & -.08 & $-.51 \star \star \star$ & .18 \\
\hline
\end{tabular}

Note. $\mathrm{AP}=$ authentic pride; $\mathrm{HP}=$ hubristic pride. Correlations were corrected for attenuation of DE-LIWC2015 reliabilities. ${ }^{*} p<.05 ;{ }^{*} p<.01$; $* * * p<.001$ (two-tailed).

$M_{\mathrm{AP}-\text { self }}=20.53(S D=16.47, M d n=16.00), M_{\mathrm{HP}-\text { self }}=$ $17.82(S D=14.10, M d n=14.00), M_{\text {AP-peer }}=16.20(S D=$ $8.49, M d n=15.00)$, and $M_{\text {HP-peer }}=14.03(S D=9.20$, $M d n=11.00$ ) words long. In the following, we only present associations between pride and the word categories with significant patterns. A complete list of correlations between self- and peer-reported pride and word usage in self- and peer-descriptions can be found in the Online Supplement.

For the self-descriptions, AP was positively related to a general positive emotional tone $(r(182)=.21, p=.005)$ but HP was not $(r(182)=-.05, p=.500$; see Table 5$)$. Strong negative associations were found between AP and negative emotion, anxiety, and sadness words $(r s(182)<$ $-.19, p s<.010)$. By contrast, HP was rather unrelated to positive or negative emotion words, anxiety, and anger, but was positively correlated with sadness words $(r(182)=$ $.16, p=.030)$. There were no substantive correlations between the two forms of pride and drives, except for a positive association of self-rated HP with the usage of achievement words $(r(182)=.27, p<.001)$.

In peer-descriptions, peer-rated $\mathrm{AP}$, like the self-reports, was positively correlated with a general positive emotional tone $(r(107)=.19, p=.043)$. The association between AP and clout, which represents social status and self-esteem, was also positive $(r(107)=.33, p<.001)$ and stronger than the association of HP with words related to clout $(r(106)=$ $.10, p=.303 ; Z=2.27, p=.012)$. AP was negatively correlated with negative emotion and anxiety words $(r s(107)<$ -.32 , ps <.001). By contrast, HP was positively correlated with negative emotion words $(r(106)=.20, p=.040)$. Regarding drives, AP was positively associated with affiliation, achievement, and reward $(r s(107)=.20, p s<.033)$, and negatively associated with risk words $(r(107)=-.51$, 
$p<$.001). HP was positively correlated with achievement, power, reward, and risk words $(r s(106)>.22$, $p s<.019)$.

\section{Discussion}

Altogether, we found that the GAHPS showed the expected correlations with aggression and psychopathy. Yet, Machiavellianism was unrelated to HP, suggesting that HP cannot simply be explained by an overall dark personality core. Future studies should test this association with additional scales as our correlation for Machiavellianism was different from Tracy et al.'s (2009). Prosociality was weakly negatively related to HP. Interestingly, only prosociality toward strangers but not toward friends was positively correlated with AP. Thus, people will behave in similar ways toward a friend, but when a stranger is in need, specifically, people with high AP tend to act prosocially. This evidence adds to previous assumptions that describe $\mathrm{AP}$ as a prosocial trait (Tracy \& Robins, 2007; Wubben et al., 2012), but the type of interpersonal relationship seems to moderate the effect.

In line with Liu et al. (2016), we found high SOA for AP but not for HP in well-acquainted dyads. In future studies, round-robin designs and interpersonal perception criteria (e.g., consensus or accuracy; see Funder \& West, 1993) could be useful for further insights because selecting peers by targets may lead to a positivity bias in peer-reports, too. Moreover, differences in observability (e.g., people have more information about themselves than their peers do, which may reduce self-peer agreement as compared with peer-peer agreement) and social desirability may be accounted for in upcoming studies to investigate reasons for the different SOA coefficients for the two forms of pride. Perhaps HP is more strongly affected by socially desirable responding in the target and by liking between the target and the acquaintance than AP is, which is why we found no mean differences for HP and only low SOA coefficients.

We found a series of substantial associations between pride and word usage. The higher the AP score was, the less likely the negative emotion words were to occur in self-and peer descriptions. Apparently, high AP is not associated with emotions such as anxiety and sadness. HP showed the reverse pattern. The correlational pattern regarding drives was less clear: Peers used more affiliation-related words when the target was high in AP, but for the targets, no such relation was found. Moreover, several drive-related words in peer descriptions were associated with peer-rated pride. For example, achievement words were positively related to HP. Still, with a more objective indicator in Study 2, we found no association between SES (as an achievement marker) and HP. Thus, although people high in HP objectively do not achieve more in life, perceived achievements seem relevant to how they and others assess themselves. Perhaps boasting about or overstating one's past accomplishments can explain such associations (see also Schütz et al., 2004).

\section{GAHPS-S - The Short Form of the GAHPS}

Sometimes assessment time is scarce. To provide a measure for such purposes, we developed a short form (GAHPS-S) with data from Study 1. First, we examined the interitem correlation matrix to exclude redundant items $(r>.80 ;$ Kline, 1979). There was no interitem correlation $>$ .80 , but AP Items 1 and 8 were correlated .79 , and as the items had similar content, we removed Item 1 from the short scale. Further, we excluded Item 7 because it was too similar to self-esteem, and we aimed to avoid strong overlap with self-esteem on the AP short scale. The remaining five AP and seven HP items were then entered into an Ant Colony Optimization algorithm (Max-Min-Ant-System; Janssen et al., 2017). The algorithm selects items that lead to the best reliability and model fit. To this end, we used the R package stuart (Schultze, 2018).

Items 6, 8, and 10 for $\mathrm{AP}$, and 2, 3, and 12 for $\mathrm{HP}$ (see Table 1) were found to provide the optimal solution. Satisfactory model fit of the GAHPS-S supported the use of CFA in Study $1, \chi^{2}(8)=4.677, p=.792$; RMSEA $=$ $.000,90 \%$ CI $[.000, .032], p=.994$; CFI $=1.000$; TLI $=$ 1.000, and in Study 2, $\chi^{2}(8)=6.804, p=.558 ;$ RMSEA $=$ $.000,90 \%$ CI $[.000, .044], p=.975$; CFI $=1.000$; TLI $=$ 1.000. Internal consistencies were acceptable in all studies (AP: $M \alpha=.73 / M \omega=.74 ; \mathrm{HP}: M \alpha=.82 / M \omega=.83$ ).

We then tested associations between these items and all the constructs from the present studies. The GAHPS-S showed the same nomological validity as the standard form (see Tables S4 and S5 in the Online Supplement). Thus, the GAHPS-S can be considered a valid and reliable instrument. It can be used in a panel and longitudinal research, in experiments, or when time is too short of using the standard form. Yet, when higher reliability and broader construct coverage are desired, the standard form should be used. Please note that participants responded to the GAHPS, not the GAHPS-S. As additional items may affect a scale's psychometric properties, future research will benefit from employing only the short-scale items and will be able to provide further evidence of validity.

\section{General Discussion}

In the present studies, satisfactory psychometric properties and broad evidence of validity were found for the GAHPS scores. Internal consistency was high across all studies for 
the GAHPS, the GAHPS-S, and the peer-rating version. Moreover, we found good model fit, measurement invariance across gender, and high temporal stability.

AP and HP were associated with different personality profiles, emotions, status strategies, and attitudes. AP showed the strongest associations with extraversion, emotional stability, self-esteem, prestige, and optimism, thus highlighting the positive evaluative component of this form of pride. HP was related to disagreeableness, grandiose narcissism, dominance, aggression, malicious envy, and greed, thus demonstrating the antisocial, hostile, and self-aggrandizing nature of that form of pride. Evidence for validity was largely in line with past research (e.g., Tracy \& Robins, 2007; Tracy et al., 2009; Rogoza et al., 2018). Yet, two aspects (pride and PA/NA; AP and greed) should be more thoroughly investigated in upcoming studies. The present research adds to the scope of the A\&HP model in showing important relations with additional variables: greed, SES, and optimism. The positive association between AP and SES can be interpreted as support for criterion validity because AP as the affective core of prestige should be more strongly related to SES than HP. The causal direction in this link is an issue for future studies employing longitudinal or experimental designs.

In line with another study (Liu et al., 2016), SOA was higher for AP than HP and remained stable when control variables related to acquaintance were added. This finding is the first evidence of diverging SOA coefficients for the two forms of pride in Western cultures.

Also for the first time, we presented linguistic correlates of both forms of pride. Tracy and Robins (2004) noted, "selfconscious emotions may be expressed more frequently through language than through nonverbal expressions" (p. 108). This underscores the relevance of studying A\&HP in language usage because self-report biases may be less present in such indirect forms of assessment. We found that people used different words to describe the respective level of A\&HP. Future research may build on these findings and test whether A\&HP moderated word usage in certain situations (e.g., after performance failures) or further investigate the interpersonal perception of A\&HP based on linguistic cues in zero-acquaintance settings.

Additionally, we can offer a valid and reliable short form: the GAHPS-S. Researchers may benefit from using this scale. For example, German panel studies that wish to include a pride measure may use this scale. For a balanced item selection, we combined up-to-date statistical methods with theoretical considerations.

Limitations refer to the overrepresentation of female participants in the samples. Aiming at gender-balanced samples in future studies could increase confidence in the findings. Moreover, in measuring certain constructs, we relied on objective indicators (affect, SES, prosociality); nevertheless, future research will benefit from testing the validity of the scale with actual behavior because we mostly used self-report instruments. Future research should also assess the temporal stability of the GAHPS across longer periods of time (e.g., 6 months) with large samples.

Finally, answers may be affected by impression management. To prevent this, researchers can use additional data sources (e.g., informant reports, linguistic data) and test for these convergence with self-reported pride. It is also informative to have participants complete the questionnaire twice: once with standard instructions and once with faking good instructions (e.g., Roth \& Herzberg, 2007).

Overall, the results of analyses based on four independent samples provide evidence for the good psychometric properties of the GAHPS and the GAHPS-S. Several additional insights regarding SOA, linguistic correlates, and validity support the relevance of the A\&HP model for interpersonal perception and communication and the explanatory power of the A\&HP model and the GAHPS.

\section{References}

Back, M. D., Küfner, A. C., Dufner, M., Gerlach, T. M., Rauthmann, J. F., \& Denissen, J. J. (2013). Narcissistic admiration and rivalry: Disentangling the bright and dark sides of narcissism. Journal of Personality and Social Psychology, 105(6), 10131037. https://doi.org/10.1037/a0034431

Beauducel, A., \& Herzberg, P. Y. (2006). On the performance of maximum likelihood versus means and variance adjusted weighted least squares estimation in CFA. Structural Equation Modeling, 13(2), 186-203. https://doi.org/10.1207/ s15328007sem1302_2

Brauer, K., \& Proyer, R. T. (2020). Judging dispositions toward ridicule and being laughed at from short self-descriptions at zero-acquaintance: Testing self-other agreement, consensus, and accuracy. Journal of Research in Personality, 89, Article 104016. https://doi.org/10.1016/j.jrp.2020.104016

Browne, M. W., \& Cudeck, R. (1993). Alternative ways of assessing model fit. In K. A. Bollen \& J. S. Long (Eds.), Testing structural equation models (pp. 136-162). Sage. https://doi.org/10.1177/ 0049124192021002005

Campbell, D. T., \& Fiske, D. W. (1959). Convergent and discriminant validation by the multitrait-multimethod matrix. Psychological Bulletin, 56, 81-105. https://doi.org/10.1037/h0046016

Carver, C. S., Sinclair, S., \& Johnson, S. L. (2010). Authentic and hubristic pride: Differential relations to aspects of goal regulation, affect, and self-control. Journal of Research in Personality, 44(6), 698-703.

Cheng, J. T., Tracy, J. L., \& Henrich, J. (2010). Pride, personality, and the evolutionary foundations of human social status. Evolution and Human Behavior, 31(5), 334-347. https://doi.org/ 10.1016/j.evolhumbehav.2010.02.004

Cheung, G. W., \& Rensvold, R. B. (2002). Evaluating goodness-offit indexes for testing measurement invariance. Structural Equation Modeling, 9(2), 233-255. https://doi.org/10.1207/ S15328007SEM0902_5

Cohen, J. (1988). Statistical power analysis for the behavioral sciences (2nd ed.). Erlbaum. 
Costello, T. H., Unterberger, A., Watts, A. L., \& Lilienfeld, S. O. (2018). Psychopathy and pride: Testing Lykken's hypothesis regarding the implications of fearlessness for prosocial and antisocial behavior. Frontiers in Psychology, 9, Article 185. https://doi.org/10.3389/fpsyg.2018.00185

Funder, D. C., \& West, S. G. (1993). Consensus, self-other agreement, and accuracy in personality judgment: An introduction. Journal of Personality, 61(4), 457-476.

Glaesmer, H., Hoyer, J., Klotsche, J., \& Herzberg, P. Y. (2008). Die deutsche Version des Life-Orientation-Tests (LOT-R) zum dispositionellen Optimismus und Pessimismus [The German version of the Life-Orientation Test (LOT-R) on dispositional optimism and pessimism]. Zeitschrift für Gesundheitspsychologie, 16(1), 26-31. https://doi.org/10.1026/0943-8149. 16.1.26

Guido, G., Amatulli, C., Peluso, A. M., De Matteis, C., Piper, L., \& Pino, G. (2020). Measuring internalized versus externalized luxury consumption motivations and consumers' segmentation. Italian Journal of Marketing, 2020(1), 24-47. https://doi.org/ 10.1007/s43039-020-00002-9

International Test Commission. (2017). The ITC guidelines for translating and adapting tests (2nd ed.). https://www.InTestCom.org

Janssen, A. B., Schultze, M., \& Grötsch, A. (2017). Following the ants: Development of short scales for proactive personality and supervisor support by Ant Colony Optimization. European Journal of Psychological Assessment, 33(6), 409-421. https:// doi.org/10.1027/1015-5759/a000299

Jones, D. N., \& Paulhus, D. L. (2014). Introducing the Short Dark Triad (SD3) a brief measure of dark personality traits. Assessment, 21(1), 28-41. https://doi.org/10.1177/1073191113514105

Kelley, K. (2018). The MBESS R package (Version 4.4.3) [R package]. http://cran.r-project.org

Kline, P. (1979). Psychometrics and psychology. Academic Press. Körner, A., Geyer, M., Roth, M., Drapeau, M., Schmutzer, G., Albani, C., Schumann, S., \& Brähler, E. (2008). Persönlichkeitsdiagnostik mit dem Neo-Fünf-Faktoren-Inventar: Die 30-Item-Kurzversion (NEO-FFl-30) [Personality diagnostics with the Neo-Five Factor Inventory: The 30-Item short version]. Psychotherapie Psychosomatik Medizinische Psychologie, 58(6), 238-245. https://doi.org/10.1055/s-2007-98619

Körner, R., Heydasch, T., \& Schütz, A. (2021). It's all about power: Validation of trait and state versions of the German Personal Sense of Power Scale. European Journal of Psychological Assessment. Advance online publication. https://doi.org/ 10.1027/1015-5759/a000642

Körner, R., \& Schütz, A. (2021). Data, syntax, and materials to The German Standard and Short Authentic and Hubristic Pride Scales: Psychometric properties, validity testing, self-other agreement, and linguistic correlates. https://osf.io/eh7r4/

Lampert, T., Kroll, L., Müters, S., \& Stolzenberg, H. (2013). Messung des sozioökonomischen Status in der Studie zur Gesundheit Erwachsener in Deutschland (DEGS1) [Measurement of socioeconomic status in the study on the Health of Adults in Germany (DEGS1)]. Bundesgesundheitsblatt-Gesundheitsforschung-Gesundheitsschutz, 56(5-6), 631-636. https:// doi.org/10.1007/s00103-012-1663-4

Lange, J., \& Crusius, J. (2015a). The tango of two deadly sins: The social-functional relation of envy and pride. Journal of Personality and Social Psychology, 109(3), 453-472.

Lange, J., \& Crusius, J. (2015b). Dispositional envy revisited: Unraveling the motivational dynamics of benign and malicious envy. Personality and Social Psychology Bulletin, 41(2), 284294. https://doi.org/10.1037/pspi0000026

Leiner, D. J. (2019). Too fast, too straight, too weird: Non-reactive indicators for meaningless data in internet surveys. Survey
Research Methods, 13(3), 229-248. https://doi.org/10.18148/ srm/2019.v13i3.7403

Liu, C., Yuan, L., Chen, C., \& Yu, G. (2016). Authentic and hubristic pride as assessed by self, friends, and strangers. Social Psychological and Personality Science, 7(7), 690-696. https:// doi.org/10.1177/1948550616649240

Liu, Z., Sun, X., \& Tsydypov, L. (2019). Scarcity or luxury: Which leads to adolescent greed? Evidence from a large-scale Chinese adolescent sample. Journal of Adolescence, 77, 32-40. https://doi.org/10.1016/j.adolescence.2019.10.002

Marsh, H. W., Hau, K. T., \& Wen, Z. (2004). In search of golden rules: Comment on hypothesis testing approaches to setting cutoff values for fit indexes and dangers in overgeneralizing $\mathrm{Hu}$ and Bentler's (1999) findings. Structural Equation Modeling, 11, 320-341. https://doi.org/10.1207/s15328007sem1103_2

McFerran, B., Aquino, K., \& Tracy, J. L. (2014). Evidence for two facets of pride in consumption: Findings from luxury brands. Journal of Consumer Psychology, 24(4), 455-471. https://doi. org/10.1016/j.jcps.2014.03.004

Pennebaker, J. W., Boyd, R. L., Jordan, K., \& Blackburn, K. (2015). The development and psychometric properties of LIWC2015. University of Texas at Austin.

Quirin, M., Kazén, M., \& Kuhl, J. (2009). When nonsense sounds happy or helpless: The Implicit Positive and Negative Affect Test (IPANAT). Journal of Personality and Social Psychology, 97(3), 500-516. https://doi.org/10.1037/a0016063

Rogoza, R., Kwiatkowska, M. M., Kowalski, C. M., \& Ślaski, S. (2018). A brief tale of the two faces of narcissism and the two facets of pride. Personality and Individual Differences, 126, 104-108. https://doi.org/10.1016/j.paid.2018.01.027

Roth, M., \& Herzberg, P. Y. (2007). The resilient type: "Simply the best" or merely an artifact of social desirability? Psychology Science, 49(2), 150-167.

Saroglou, V., Pichon, I., Trompette, L., Verschueren, M., \& Dernelle, R. (2005). Prosocial behavior and religion: New evidence based on projective measures and peer ratings. Journal for the Scientific Study of Religion, 44(3), 323-348. https://doi.org/ 10.1111/j.1468-5906.2005.00289.x

Schaumberg, R. L., \& Tracy, J. L. (2020). From self-consciousness to success: When and why self-conscious emotions promote positive employee outcomes. In L. Yang, R. Cropanzano, C. Daus, \& V. Martinez-Tur (Eds.), The Cambridge handbook of workplace affect (pp. 414-425). Cambridge University Press.

Schütz, A., Marcus, B., \& Sellin, I. (2004). Die Messung von Narzissmus als Persönlichkeitskonstrukt [The assessment of narcissism as personality trait]. Diagnostica, 50(4), 202-218. https://doi.org/10.1026/0012-1924.50.4.202

Schultze, M. (2018). Stuart: Subtests using algorithmic rummaging techniques (Version 0.8.0) [R package]. https://bitbucket. org/martscht/stuart

Seuntjens, T. G., Zeelenberg, M., Van de Ven, N., \& Breugelmans, S. M. (2015). Dispositional greed. Journal of Personality and Social Psychology, 108(6), 917-933. https://doi.org/10.1037/pspp0000031

Sullivan, G. B., \& Dumont, K. (2014). Collective pride and prejudice: A naturalistic study of the effects of group pride versus individual pride on attitudes to migrants following a national team victory. In G. B. Sullivan (Ed.), Understanding collective pride and group identity: New directions in emotion theory, research and practice (pp. 95-109). Routledge.

Tangney, J. P., Dearing, R., Wagner, P. E., \& Gramzow, R. (2000). The Test of Self-Conscious Affect - 3 (TOSCA-3). George Mason University.

Tracy, J. L., Cheng, J. T., Robins, R. W., \& Trzesniewski, K. H. (2009). Authentic and hubristic pride: The affective core of selfesteem and narcissism. Self and Identity, 8(2-3), 196-213. https://doi.org/10.1080/15298860802505053 
Tracy, J. L., \& Robins, R. W. (2004). Putting the self into selfconscious emotions: A theoretical model. Psychological Inquiry, 15(2), 103-125. https://doi.org/10.1207/s15327965pli1502_01

Tracy, J. L., \& Robins, R. W. (2007). The psychological structure of pride: A tale of two facets. Journal of Personality and Social Psychology, 92(3), 506-525. https://doi.org/10.1037/00223514.92.3.506

Von Collani, G., \& Herzberg, P. Y. (2003). Eine revidierte Fassung der deutschsprachigen Skala zum Selbstwertgefühl von Rosenberg [A revised version of the German adaptation of Rosenberg's Self-Esteem Scale]. Zeitschrift für Differentielle und Diagnostische Psychologie, 24(1), 3-7. https://doi.org/10.1024/ 0170-1789.24.1.3

Weidman, A. C., Tracy, J. L., \& Elliot, A. J. (2016). The benefits of following your pride: Authentic pride promotes achievement. Journal of Personality, 84(5), 607-622. https://doi.org/10.1111/ jopy. 12184

Werner, R., \& von Collani, G. (2014). Deutscher Aggressionsfragebogen [German Aggression Questionnaire]. GESIS.

Wubben, M. J., De Cremer, D., \& van Dijk, E. (2012). Is pride a prosocial emotion? Interpersonal effects of authentic and hubristic pride. Cognition \& Emotion, 26(6), 1084-1097. https://doi.org/10.1080/02699931.2011.646956

\section{History}

Received March 24, 2021

Revision received July 1, 2021

Accepted September 2, 2021

Published online November 19, 2021

EJPA Section / Category Personality

\section{Acknowledgment}

The authors are grateful to Gavin Sullivan for providing us with his translation of the items. Further, we thank Timo Heydasch, Marina Gruber, and Alexandra Karg for support with data collection. We thank two anonymous reviewers for their valuable comments. Finally, we thank Jane Zagorski for language editing.

\section{Conflict of Interest}

We have no conflicts of interest to disclose.

\section{Publication Ethics}

All procedures performed in studies involving human participants were in accordance with the ethical standards of the national research committee and with the 1964 Helsinki declaration and its later amendments or comparable ethical standards. This article does not contain any studies with animals performed by any of the authors. Informed consent was obtained from all participants who were included in the study.

\section{Open Science}

For all studies, we report all data exclusions, all data inclusion/ exclusion criteria, whether inclusion/exclusion criteria were established prior to data analysis, all measures in the study, and all analyses including all tested models. If we use inferential tests, we report exact $p$ values and effect sizes.

Open Data: We confirm that there is sufficient information for an independent researcher to reproduce all of the reported results. All data, syntaxes, and materials are available at https://osf.io/ eh7r4/.

Open Materials: We also confirm that there is sufficient information for an independent researcher to reproduce all of the reported methodology.

Preregistration: The studies were not preregistered.

\section{Funding}

Open access publication enabled by the University of Bamberg.

\section{ORCID}

Robert Körner

(iD) https://orcid.org/0000-0001-8793-0830

Astrid Schütz

(D) https://orcid.org/0000-0002-6358-167X

\section{Astrid Schütz}

Department of Psychology

University of Bamberg

Markusplatz 3

96047 Bamberg

Germany

astrid.schuetz@uni-bamberg.de 